\title{
Evaluation of hydrogen embrittlement and temper embrittle- ment by key curve method in instrumented Charpy test
}

\author{
N. Ohtsuka ${ }^{1, a}$, Y. Shindo ${ }^{1}$, and A. Makita ${ }^{2}$ \\ ${ }^{1}$ Dept. of Mechanical and Systems Engineering, Ryukoku University, Ohtsu 520-2123, Japan \\ ${ }^{2}$ Yamakin Kogyo Co. Ltd., Fukui 918-8002, Japan
}

\begin{abstract}
Instrumented Charpy test was conducted on small sized specimen of 2$1 / 4 \mathrm{Cr}-1 \mathrm{Mo}$ steel. In the test the single specimen key curve method was applied to determine the value of fracture toughness for the initiation of crack extension with hydrogen free, $K_{\mathrm{IC}}$, and for hydrogen embrittlement cracking, $K_{\mathrm{IH}}$. Also the tearing modulus as a parameter for resistance to crack extension was determined. The role of these parameters was discussed at an upper shelf temperature and at a transition temperature. Then the key curve method combined with instrumented Charpy test was proven to be used to evaluate not only temper embrittlement but also hydrogen embrittlement.
\end{abstract}

\section{Introduction}

Attention should be paid to oil refineries and chemical plants used at high temperature and high pressure to prevent hydrogen embrittlement and temper embrittlement. However, the mechanism and the combined effect of these two embrittlements are not always known[1,2]. Safety assessment of these plants can be evaluated in terms of fracture toughness. In order to evaluate the fracture toughness for the initiation of crack extension with hydrogen free, $K_{\mathrm{IC}}$, and for hydrogen embrittlement cracking, $K_{\mathrm{IH}}$, of 2-1/4Cr-1Mo steel by using small sized specimen, instrumented Charpy test was conducted and the value of fracture toughness and resistance to crack extension were calculated by the key curve method in the paper.

\section{Experimental procedure}

The material tested was 2-1/4Cr-1Mo steel and was treated with post-weld heat (PWHT) at $963 \mathrm{~K}$ $\left(690{ }^{\circ} \mathrm{C}\right)$ for 8 hours or with step cooling (SC) to induce temper embrittlement. The chemical compositions of the material are shown in Table 1. The Charpy test specimen was V-notched with 2 $\mathrm{mm}$ in depth or blunt U-notched with $4 \mathrm{~mm}$ in depth or fatigue pre-cracked with $4 \mathrm{~mm}$ in depth with $2 \mathrm{~mm}$ side grooves as shown in Figure 1. Transition curves of Charpy absorbed energy by using the V-notched specimen are shown in Figure 2 for PWHT material and Figure 3 for SC material.

\footnotetext{
a e-mail : ohtsuka@ rins.ryukoku.ac.jp
} 
About a half of the specimens was charged with hydrogen in an autoclave at $723 \mathrm{~K}\left(450{ }^{\circ} \mathrm{C}\right)$ and $15 \mathrm{MPa}$ for 48 hours (low pressure hydrogen charge, $\mathrm{LH}$ ) or at $723 \mathrm{~K}\left(450{ }^{\circ} \mathrm{C}\right.$ ) and $25 \mathrm{MPa}$ for 48 hours (high pressure hydrogen charge, $\mathrm{HH}$ ). Immediately after taken from the autoclave, the specimens were cooled down rapidly and kept in a canister with liquid nitrogen until starting of the test.

The test was conducted by using an instrumented Charpy test machine with a capacity of $300 \mathrm{~J}$ at a transient temperature $\left(313 \mathrm{~K}\left(40{ }^{\circ} \mathrm{C}\right)\right)$ or at an upper shelf temperature $\left(393 \mathrm{~K}\left(120{ }^{\circ} \mathrm{C}\right)\right)$. As shown in Figure 4, applied load, $P$, and displacement, $v$, of a hammer were measured by strain gauges attached on a tap and by an optical displacement meter, respectively. The oscillating loaddisplacement curves were recorded in an oscilloscope and were smoothed by averaging the curve after the test[3].

Table 1 Chemical composition of materials (wt. \%).

\begin{tabular}{|c|c|c|c|c|c|c|c|c|c|}
\hline $\mathrm{C}$ & $\mathrm{Mn}$ & $\mathrm{P}$ & $\mathrm{S}$ & $\mathrm{Si}$ & $\mathrm{Cr}$ & $\mathrm{Mo}$ & $\mathrm{Ni}$ & $\mathrm{V}$ & $\mathrm{Nb}$ \\
\hline 0.143 & 0.56 & 0.021 & 0.002 & 0.24 & 2.39 & 1.07 & 0.14 & $<0.001$ & 0.001 \\
\hline \hline $\mathrm{N}$ & $\mathrm{Al}$ & $\mathrm{Cu}$ & $\mathrm{Sn}$ & $\mathrm{As}$ & $\mathrm{Sb}$ & $\mathrm{B}$ & $\mathrm{O}$ & $\mathrm{X}$-bar & $\mathrm{J}$ \\
\hline 0.0022 & 0.017 & 0.04 & 0.001 & $<0.001$ & $<0.001$ & $<0.0001$ & 0.0011 & 29.8 & 344 \\
\hline
\end{tabular}

$X-b a r=(10 P+5 S b+4 S n+A s)^{*} 10^{-2}(p p m) \quad J=(S i+M n)(P+S n)^{*} 10^{4}($ wt. $\%)$

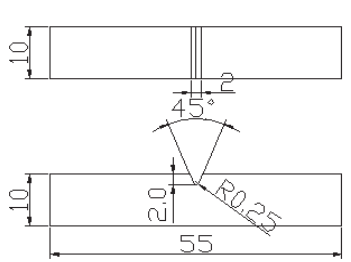

(a)

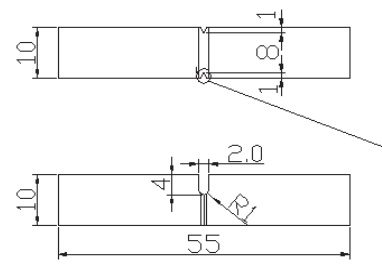

(C)

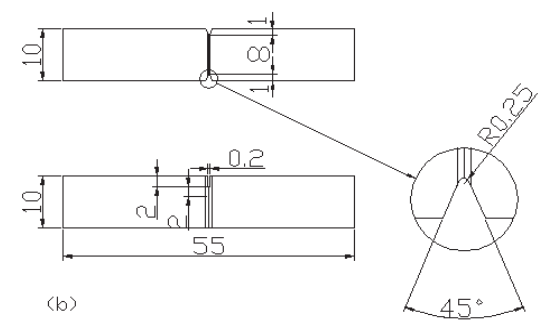

〈b)

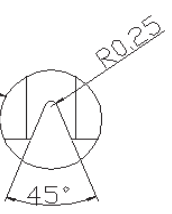

Fig.1. Confuguration of specimen (in mm) ; (a) V-notched specimen,

(b) faigue pre-cracked specimen, (c) U-notched specimen. 


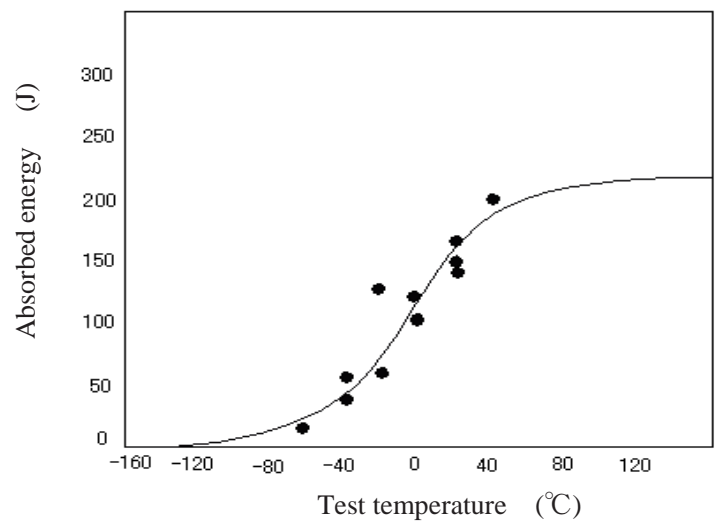

Fig.2. Transition curve of Charpy absorbed energy for PWHT (post-weld heat treated) material. $\left(0{ }^{\circ} \mathrm{C}\right.$ is $\left.273 \mathrm{~K}\right)$.

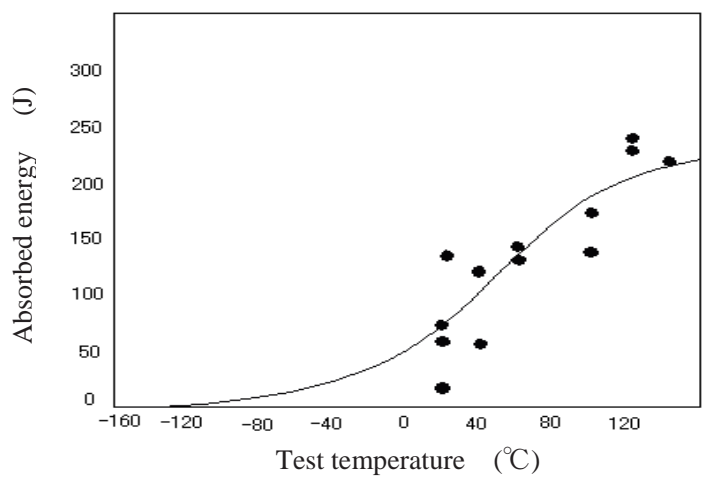

Fig.3. Transition curve of Charpy absorbed energy for SC (step cooled) material. $\left(0{ }^{\circ} \mathrm{C}\right.$ is $\left.273 \mathrm{~K}\right)$.

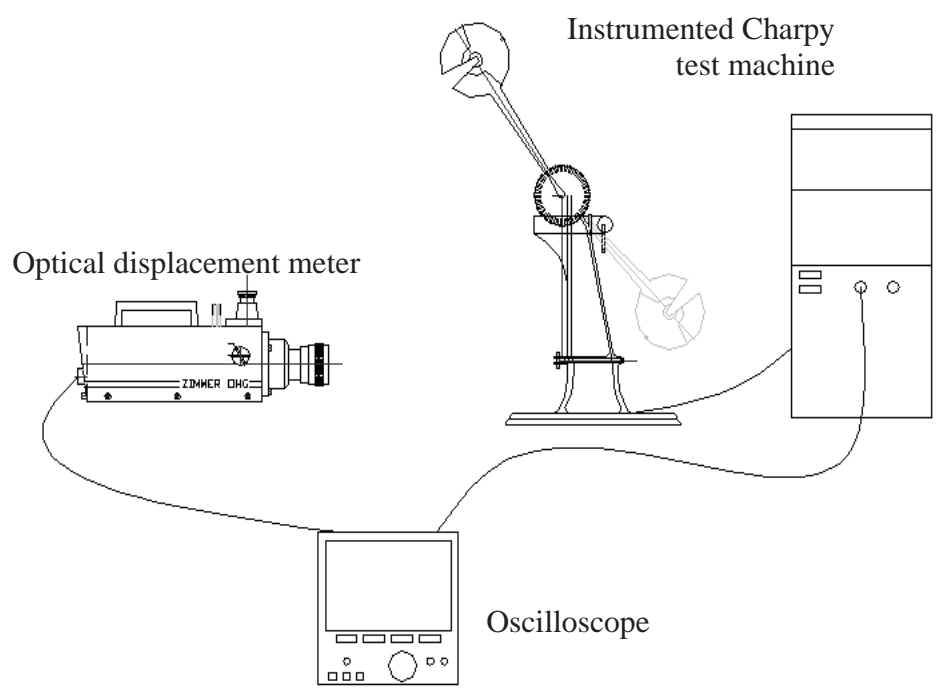

Fig.4. Schematic illustration of test installation. 
J-R curves were obtained by the single specimen key curve method as follows[4]: Denoting subscript $\mathrm{f}$ and $\mathrm{u}$ as fatigue pre-cracked and U-notched specimens, respectively, the $P-v$ curves of the two specimens were superimposed. The J-integral at any displacement of the fatigue pre-cracked specimen was calculated by

$$
J=\frac{2}{B_{N} b_{0}} \int_{0}^{v} P \cdot d v
$$

where $B_{N}$ and $b_{0}$ are a net thickness and an original uncracked ligament of the specimen, respectively. The uncracked ligament is calculated as $b_{0}=W-a_{0}$, where $W$ is a width and $a_{0}$ is an original crack length of the specimen. The corresponding crack extension $\Delta a$ is calculated as

$$
\Delta a=b_{0}\left(1-\sqrt{P_{f} / P_{u}}\right)
$$

\section{Experimental results and discussion}

\subsection{Results of key curve method}

Solid lines in Figure 5 shows an example of superimposed $P$ - $v$ records of fatigue pre-cracked (lower curve) and U-notched (upper curve) specimens of step cooled (SC) material tested at a transition temperature of $313 \mathrm{~K}\left(40{ }^{\circ} \mathrm{C}\right)$. In the figure smoothed curves of the specimens are also shown as broken lines. Figure 6 indicates an example of a J-R curve of the specimen, determined by the key curve method. The J-integral, $J$, and crack extension, $\Delta a$, are calculated by equations (1) and (2), respectively.

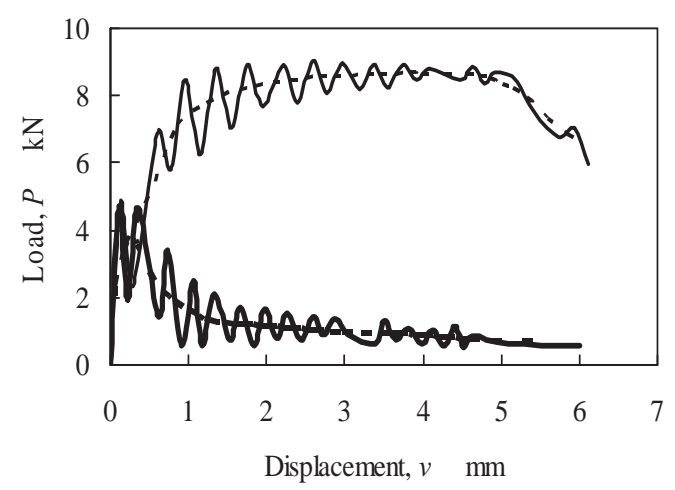

Fig.5. Superimposed $P-v$ records and the smoothed curves of fatigue pre-cracked (lower curve) and U-notched (upper curve) specimens of SC material tested at a transition temperature of $313 \mathrm{~K}\left(40{ }^{\circ} \mathrm{C}\right.$ ). 


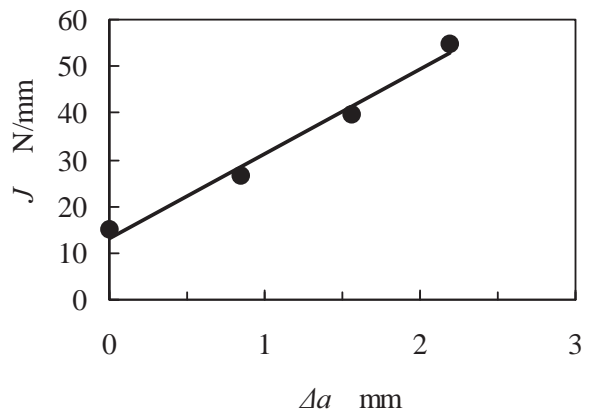

Fig.6. J-R curve of step cooled (SC) material at $313 \mathrm{~K}\left(40{ }^{\circ} \mathrm{C}\right)$.

\subsection{Fracture toughness at the initiation of crack extension and tearing modulus}

$J_{\mathrm{IC}}$ or $J_{\mathrm{IH}}$ at the initiation of crack extension for hydrogen free or for hydrogen charged material is determined as the $\mathrm{J}$ value at the intersection of $\mathrm{J}-\mathrm{R}$ curve with the ordinate as shown in Figure 6. Fracture toughness, $K_{\mathrm{IC}}$ or $K_{\mathrm{IH}}$, corresponding to $J_{\mathrm{IC}}$ or $J_{\mathrm{IH}}$ and the tearing modulus, $T_{\text {app }}$, representing the resistance to crack extension are determined by

$$
\begin{aligned}
& K_{I}=\sqrt{\frac{E J}{1-v^{2}}} \\
& T_{a p p}=\frac{E}{\sigma_{f}^{2}} \cdot \frac{d J}{d a}
\end{aligned}
$$

where $E$ is Young's modulus (206 GPa), $\nu$ is Poisson's ratio $(0.3)$ and $\sigma_{\mathrm{f}}$ is a flow stress determined as the average of yielding stress (497 MPa) and tensile strength (651 MPa) of the material. The term of $d J / d a$ indicates an inclination of the J-R curve.

Figure 7 summarizes the fracture toughness and the tearing modulus at an upper shelf temperature of $393 \mathrm{~K}\left(120{ }^{\circ} \mathrm{C}\right)$. Compared with hydrogen free post-weld heat treated material (PWHT), the value of $K_{\mathrm{IC}}$ for SC material decreased from 317 to $210 \mathrm{MPa} \sqrt{\mathrm{m}}$, which corresponds to the effect of temper embrittlement.

Although the fracture toughness, $K_{\mathrm{IH}}$, at the initiation of crack extension with charging of hydrogen had little difference from $K_{\mathrm{IC}}$ without charging of hydrogen, the tearing modulus, $T_{\text {app }}$, decreased from 353 to 114 with the charge of hydrogen. This suggests that the degradation of toughness of the test material due to hydrogen embrittlement at the upper shelf temperature of the test material is mainly caused not by the crack initiation but by the decrease of resistance to crack extension.

Hydrogen charging pressure between $15 \mathrm{MPa}(\mathrm{LH})$ and $25 \mathrm{MPa}(\mathrm{HH})$ had little effect on $K_{\mathrm{IH}}$ and the tearing modulus, $T_{\text {app }}$, at the upper shelf temperature. 


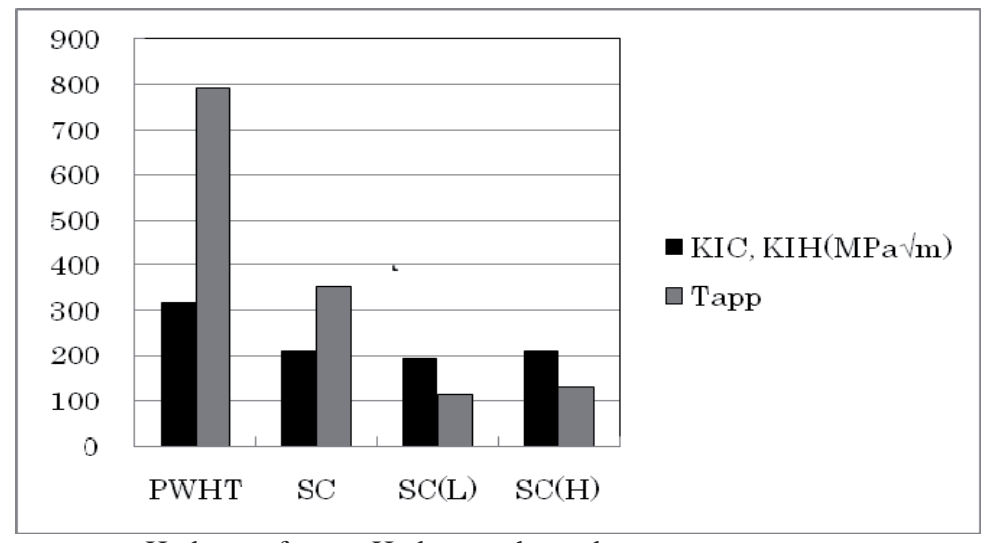

Hydrogen free Hydrogen charged

Fig.7. Comparison of fracture toughness and the tearing modulus at an upper shelf temperature of $393 \mathrm{~K}\left(120^{\circ} \mathrm{C}\right)$.

Figure 8 compares the fracture toughness and the tearing modulus at an transition temperature of $313 \mathrm{~K}\left(40{ }^{\circ} \mathrm{C}\right)$. The values of $K_{\mathrm{IC}}$ and especially the tearing modulus for hydrogen free and step cooled (SC) material decreased significantly from post-weld heat treated material (PWHT) at the transition temperature, which indicates the effect of temper embrittlement is more distinguished at a transition temperature than at an upper shelf temperature mainly due to the decrease of resistance to crack extension.

Although the fracture toughness of step cooled (SC) material showed little difference by charging of low pressure hydrogen charge (LH) at the transition temperature of $313 \mathrm{~K}$, the tearing modulus, $T_{\text {app }}$, decreased from 11 to 7 with the charge of low pressure hydrogen (LH), and further to 4 with high pressure hydrogen charge $(\mathrm{HH})$. This proves that the hydrogen embrittlement of the test material at a transition temperature of is caused mainly by the lowering of resistance to crack extension rather than the resistance to the initiation of crack extension, except for the case of high pressure hydrogen charge $(\mathrm{HH})$.

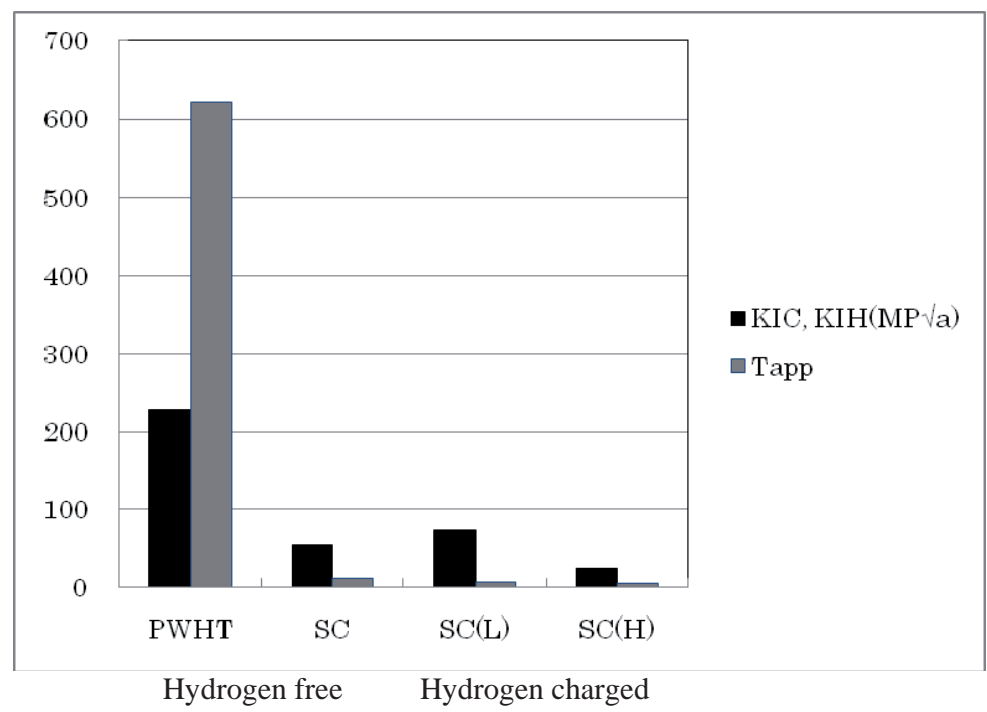

Fig.8. Comparison of fracture toughness and the tearing modulus at an upper shelf temperature of $313 \mathrm{~K}\left(40{ }^{\circ} \mathrm{C}\right)$. 


\section{Conclusions and acknowledgement}

In the paper the key curve method using small size and number of specimens was applied to the instrumented Charpy test of 2-1/4Cr-1Mo steel which was subjected to temper embrittlement and/or hydrogen embrittlement. The results indicated that the method is capable to measure the fracture toughness, $K_{\mathrm{IC}}$ with hydrogen free, and $K_{\mathrm{IH}}$ with hydrogen charged, and the tearing modulus, $T_{\text {app}}$, which is an index of a resistance to crack extension. It is considered to be worth notice that the method can be applied not only at the upper shelf and transition temperatures but also to hydrogen embrittled materials.

The study was supported by the Subcommittee on Hydrogen Embrittlement of the Japan Pressure Vessel Research Council. The authors express many thanks to donation of specimens and useful discussions by the members of the subcommittee.

\section{References}

1. Welding Research Council, Embrittlement of Pressure Vessel Steels in High Temperature, High Pressure Hydrogen Embrittlement, Bulletin 305, (1985)

2. JPVRC, Measurement Method and Evaluation of the Hydrogen Embrittlement Threshold Stress Intensity Factor (KIH) for 2.25Cr-1Mo Steel, JPVRC S/C on Hydrogen Embrittlement (TG5) report, (1989)

3. N. Ohtsuka, N. Urabe, Preprints of ECF8 (EMAS), 3, 1727(1990)

4. N. Ohtsuka, Y. Matsumoto, Trans. JSME, 53, 491A, 1419(1987) (in Japanese) 